\title{
Pediatric continuous-flow left ventricular assist devices: No longer just a bridge? The changing of a mindset!
}

\author{
Chet R. Villa, MD, Angela Lorts, MD, and David L. S. Morales, MD
}

From The Heart Institute, Cincinnati Children's Hospital Medical Center, Cincinnati, Ohio.

Disclosures: D.L.S.M. is a consultant for Berlin Heart, Heartware, and Syncardia. All other authors have nothing to disclose with regard to commercial support.

Received for publication May 4, 2017; accepted for publication May 8, 2017; available ahead of print June 9, 2017.

Address for reprints: David L. S. Morales, MD, The Heart Institute at Cincinnati Children's Hospital Medical Center, 3333 Burnet Ave, MLC 2004, Cincinnati, OH 45229 (E-mail: David.Morales@ cchmc.org).

J Thorac Cardiovasc Surg 2017;154:1362-3

$0022-5223 / \$ 36.00$

Copyright $₫ 2017$ by The American Association for Thoracic Surgery

http://dx.doi.org/10.1016/j.jtcvs.2017.05.014

Dr Adachi has nicely described the past, present, and future (potential) use of continuous-flow ventricular assist devices (CFVADs) in children. ${ }^{1} \mathrm{He}$ also describes how the reliability and side-effect profile of CFVADs, as well as the fact that they enable patients to be discharged to their homes, have altered patient management. These advantages have led centers to preferentially implant CFVADs over pulsatile ventricular assist devices (VADs) in children weighing $25 \mathrm{~kg}$ or more, ${ }^{2}$ despite limited data regarding the off-label use of these devices. Recent case series, ${ }^{3}$ as well as the recent study from Pediatric Interagency Registry for Mechanical Circulatory Support, ${ }^{4}$ support this approach. The early, positive experience has led some centers to implant CFVADs in children weighing less than $25 \mathrm{~kg}$, but it remains unclear whether the positive outcomes, especially the lower complication rate, apply to the smaller size patients. The "positive" case series to date have already reported a higher stroke rate.

Since our community began implanting "adult" intracorporeal devices in preteens, we have used "virtual implantation" to help assess device fit. This method is now widely used and has been accepted as a fit criterion for a Food and Drug Administration trial of the Syncardia-50/50cc Total Artificial Heart. ${ }^{6}$ In the coming years, the use of gross anatomic measurements, such as weight and body surface area, will begin to wane clinically and in device development. The pediatric VAD field will continue to evolve as new CFVADs are developed. The Pumps for Kids-InfantsNeonates trial, which will launch in the coming months, will offer an AA battery-sized, axial-flow CFVAD (Jarvik-Infant; Jarvik Heart Inc, New York, NY) to children weighing 8 to $20 \mathrm{~kg}$.

The development of reliable, smaller CFVAD technology with a better morbidity profile has allowed our field to mature especially in regard to patient selection, implant timing, and less use of biventricular VADs, resulting in improved outcomes. This, coupled with the ability to discharge patients to their homes, prompted Dr Adachi to note that "VAD support may be accepted as a stand-alone

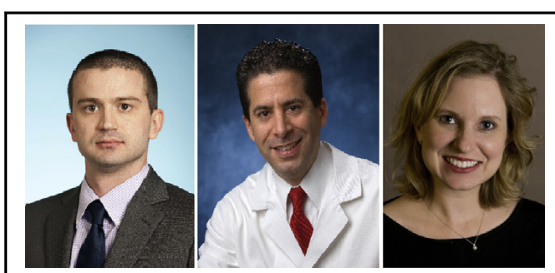

Chet R. Villa, MD, David L. S. Morales, MD, and Angela Lorts, MD

Central Message

Pediatric CFVAD support has dramatically improved outcomes. Our mindset and use of the devices must evolve along with the devices.

See Article page 1358 .

therapy for medically resistant heart failure requiring hospitalization, akin to a pacemaker implant in pacing-dependent patients." 1 The adult VAD community has clearly moved in this direction, as surgeons implant VADs in progressively "less ill" patients. ${ }^{7}$ The pediatric community no longer needs to see CFVADs as a bridge to something, but rather as a therapeutic tool in the management of medically resistant heart failure. When we place a pacemaker for a patient in the hospital for a pacing-dependent lesion, we do not have to state the intention of that pacemaker (ie, bridge to a percutaneous pacemaker or destination pacemaker). It is just a pacemaker.

Our understanding and use of CFVADs in children continues to grow but is far from complete. However, we should acknowledge the revolutionary nature of these devices and the rapid evolution that has occurred in our field. In less than 5 years (2013), we have matured from a situation in which 2 to 3 independent pediatric VAD centers were implanting VADs in patients and discharging patients with CFVADs across the world to the current day when more than $50 \%$ of VADs implanted in children are CFVADs. CFVADs continue to be used almost exclusively as a bridge to transplant in children ${ }^{8}$; however, it seems that this mindset is changing daily.

\section{References}

1. Adachi I. Continuous-flow ventricular assist device support in children: a paradigm change. J Thorac Cardiovasc Surg. 2017;154:1358-61.

2. Blume ED, Rosenthal DN, Rossano JW, Baldwin JT, Eghtesady P, Morales DL, et al. Outcomes of children implanted with ventricular assist devices in the United States: first analysis of the Pediatric Interagency Registry for Mechanical Circulatory Support (PediMACS). J Heart Lung Transplant. 2016;35:578-84. 
3. Miera O, Kirk R, Buchholz H, Schmitt KR, VanderPluym C, Rebeyka IM, et al. multicenter study of the HeartWare ventricular assist device in small children. $J$ Heart Lung Transplant. 2016;35:679-81.

4. Rossano JW, Lorts A, VanderPluym CJ, Jeewa A, Guleserian KJ, Bleiweis MS, et al. Outcomes of pediatric patients supported with continuous-flow ventricular assist devices: a report from the Pediatric Interagency Registry for Mechanical Circulatory Support (PediMACS). J Heart Lung Transplant. 2016;35:585-90.

5. Conway J, Miera O, Henderson HT, VanderPluym C, Buchholz H, Fenton M, et al. Global experience with the Heartware HVAD in pediatric patients: a preliminary analysis. J Heart Lung Transplant. 2016;35(suppl):S45.
6. Moore RA, Lorts A, Madueme PC, Taylor MD, Morales DL. Virtual implantation of the 50cc SynCardia total artificial heart. J Heart Lung Transplant. 2016;35: 824-7.

7. Starling RC, Estep JD, Horstmanshof DA, Milano CA, Stehlik J, Shah KB, et al; ROADMAP Study Investigators. Risk assessment and comparative effectiveness of left ventricular assist device and medical management in ambulatory heart fail ure patients: the ROADMAP study 2-year results. JACC Heart Fail. March, 30 2017 [Epub ahead of print].

8. PediMACS. Quarterly Statistical Report: 2016 Q4. Available at: https://www.uab edu/medicine/intermacs/images/Federal_Quarterly_Report/Pedimacs_-_Federal_ Partners_Report_2016_Q4.pdf. Accessed April 20, 2017. 